\title{
ASPECTOS IMUNOLÓGICOS RELACIONADOS ÀS DOENÇAS INCIDENTES NA PRÁTICA ODONTOLÓGICA: REVISÃO DE LITERATURA
}

\section{ARTIGO DE REVISÃO}

NERO, Nayara Rúbio Diniz Del ${ }^{1}$

DINIZ, Dhandara Rúbio ${ }^{2}$

NERO, Nayara Rúbio Diniz Del. DINIZ, Dhandara Rúbio. Aspectos imunológicos relacionados às doenças incidentes na prática odontológica: Revisão de literatura. Revista Científica Multidisciplinar Núcleo do Conhecimento. Ano 05, Ed. 10, Vol. 15, pp. 48-57. Outubro de 2020. ISSN: 2448-0959, Link de acesso: https://www.nucleodoconhecimento.com.br/odontologia/doencas-incidentes

\section{RESUMO}

O microbioma do corpo humano abriga uma extensa comunidade de microorganismos que interagem com o hospedeiro imunologicamente competente, podendo inclusive favorecer suas ações fisiológicas. Entretanto, essas colônias microbianas têm potencial de nocividade, inclusive aquela presente na cavidade oral, sendo capaz de se expressar intensamente em casos de desajuste momentâneo ou crônico do sistema de defesa humano. As doenças de maior incidência na cavidade oral, periodontite e cárie dentária, são processos patológicos com envolvimento microbiano e tem no sistema imune do paciente um grande combatente ao seu desenvolvimento, seja como barreira preventiva ou com ações diretas de resposta defensiva. Ambas as condições patológicas foram apontadas neste artigo, exaltando

1 Doutoranda em Imunologia e Parasitologia PIPA/UFU, Mestre em Patologia Clínica/UFTM, Graduação em Odontologia, Docente Odontologia/UMA.

${ }^{2}$ Biomédica, Especialista em Análises Clínicas e Bioquímica/FTH e Diagnósticos por Imagem/UNIUBE. 
a necessidade da observação do cirurgião-dentista sobre os aspectos imunológicos de impacto na saúde bucal. Foi feito levantamento bibliográfico delimitado pelo temaos aspectos imunológicos que impactam a prática odontológica, através dos bancos de dados das plataformas digitais Google Acadêmico e PubMed; para a realização desta revisão bibliográfica. Baseando-se nos apontamentos científicos levantados por este trabalho, sugere-se a perspectiva que; a análise dos aspectos imunológicos associada aos diagnósticos e tratamentos odontológicos propostos pode oferecer uma complementação de argumentos e abordagens que poderiam ser muito mais assertivos e efetivos na rotina clínica.

Palavras-chave: imunologia, imunologia odontológica, microbioma oral.

\section{INTRODUÇÃO}

O microbioma do corpo humano é composto por uma complexidade de microorganismos que são localizados nos mais diversos locais, com características comunitárias específicas (SHREINER; KAO; YOUNG, 2015). Essas comunidades de micróbios são percebidas em regiões como pele, trato gastrointestinal, trato urinário e cavidade oral (AGUIAR et al., 2016).

O microbioma da cavidade oral é composto por diferentes micróbios, inclusive bactérias, que, em relação de mutualismo com um hospedeiro imunologicamente saudável, este complexo de micro seres pode oferecer benefícios, como facilitar a digestão, resistência à colonização inoportunas e participação na síntese de vitaminas (DAGLI et al, 2016).

A presença do biofilme dental pode ser um grande facilitador de doenças bucais, por favorecerem a interação entre os micróbios, dieta do hospedeiro e o próprio indivíduo (FLEMMING et al., 2006). Além destes fatores, David et al. (2014) incluem outros, como condições sistêmicas, imunológicas ou ainda o uso de medicamentos que diminuiriam a salivação, possibilitando a propagação e aderência de microorganismos ao biofilme. 
A cavidade oral possui, no seu epitélio de revestimento, uma barreira física contra agentes agressores, inclusive micro-organismos com potencial de nocividade (CHUNG et al., 2004). Havendo invasão microbiana, o sistema imunológico do paciente saudável entra em ação e através de diferentes estratégias, combate e restringe a expansão da infecção, contendo os agravos ao organismo (DEAS; MACKEY e MCDONNELL, 2003).

O levantamento e apontamento preciso da microbiota envolvida na injúria bucal é fundamental para o diagnóstico clínico do paciente e proposta de tratamento, além de permitir a inter-relação dos patógenos com os biomarcadores do sistema de defesa do indivíduo, objetivando o rastreamento e atuação, a partir destes dados, na prevenção da doença, diagnóstico preciso e no desenvolvimento do plano de tratamento especializado (NAIFF; ORLANDI; SANTOS, 2012).

As opções atuais da maioria da população por dietas ricas em carboidratos, logo, de grande potencial cariogênio, tornam o sistema de controle e defesa imune praticamente incapaz de conter o desenvolvimento da doença cárie (AKIYOSHI et al., 1998).

O sistema imunológico desempenha um papel chave no desenvolvimento das doenças periodontais, estando alguns de seus mediadores e células de defesa presentes a partir do início da gengivite (BARTOLD et al., 2010). Também há grande participação do sistema imunológico no ciclo de remodelação óssea no indivíduo sadio (LOPES et al., 2008).

\section{REVISÃO DE LITERATURA}

Os microbiomas encontrados em diferentes locais do organismo humano são comuns e não alteram agressivamente o processo da fisiologia, sendo que cada uma destas comunidades desempenha suas funções agregadas, correlacionando-se com o estado de saúde do paciente, dieta e higiene. O grau de complexidade e de correlação desse microbioma com o indivíduo, em regime de simbiose, depende de fatores, como base do sítio anatômico, funções agregadas (RENDINBO, 2014) e idade do 
hospedeiro (LEUNG e POULIN, 2008). Nesta perspectiva, a presença de certos microorganismos na nossa estrutura física não é nociva, além de trazer benefícios para ambos os envolvidos na relação mutualística, inclusive o humano (URSEL et al, 2012).

Wang et al. (2017) ressaltam que os micróbios componentes dos diversos microbiomas humanos tem potencial de nocividade, podendo ser potencializado por uma incompetência esporádica ou crônica do sistema imunológico. Em caso de descontrole dessas colônias complexas, as doenças causadas por estes patógenos têm uma oportunidade para se espalhar por outras áreas do corpo humano.

As doenças da cavidade oral de maior incidência são cárie dental e doença periodontal, podendo ser encontradas em pacientes totalmente ou parcialmente dentados e em todas as faixas etárias (MARSH, 2000).

Segundo Zarco et al. (2012), a cárie dental tem a maior incidência entre as doenças bucais. A ela também é atribuída as mais comuns sintomatologias na boca, como dor espontânea e perda de função. De caráter multifatorial e colonização bacteriana, esta patologia pode acometer pacientes dentados em todas as faixas etárias e dentaduras presentes- decídua, mista ou permanente, comprometendo estruturas da coroa ou raiz dental (SELWITZ et al., 2007).

O sistema de defesa inespecífico na cavidade oral se manifesta através da interação das proteínas presentes na saliva. Estas proteínas possuem capacidade de memória imune e controlam a presença de micro-organismos, inclusive a colônia bacteriana (LOESCHE, 1993). Estas proteínas protetoras atuam junto à outras propriedades da saliva dificultando a adesão bacteriana ao biofilme. Segundo Tellefson e Germaine (1986), esta ação imunoprotetora tem sido cada vez menor, graças a resistência bacteriana, especialmente em indivíduos com dietas ricas em carboidratos.

O comportamento resistente da microbiota dos biofilmes à antimicrobianos e ao sistema de defesa do hospedeiro tem sido relatado por Hobley et al. (2015). As propriedades da matriz do biofilme maduro podem conferir proteção para suas bactérias, potencializando a resistência bacteriana (XIAO et al., 2012). 
$\mathrm{Na}$ presença de biofilme sobre a estrutura dentária e dieta rica em açúcares, a composição do biofilme torna-se mais propensa a favorecer a metabolização dos carboidratos pelas colônias de micro-organismos presentes na área. O resultado do processamento excessivo de açúcares simples é a eliminação de ácidos que resultam na descalcificação da superfície dentária: estágio inicial da doença cárie (PITTS, 2017).

Uma expressão imune que pode retardar o desenvolvimento da lesão cariosa é a presença da imunoglobulina IgA secretora (IgA-s). Esta apresenta uma maior resistência às enzimas proteolíticas da cavidade oral ((MORRIER e BARSOTTI, 1990). IgA-s cobre a superfície das bactérias, impedindo que as mesmas consigam se aderir à película adquirida do esmalte, no potencial fase inicial de desenvolvimento do biofilme (TENOVUO, 1997). Entretanto, segundo Yazaki et al. (1999), quando as bactérias já estão aderidas ao dente, a ação protetora da IgA-s torna-se insignificante.

Outra possibilidade de intervenção imunológica para a contenção do desenvolvimento da cárie foi proposta por Sato et al. (2002), ao proporem o estudo do antígeno III (ou antígeno A), observado na parede celular do S. mutans. O isolamento da ação deste antígeno poderia dificultar a adesão bacteriana à superfície dentária, opinião compartilhada por Koga et al. (2002).

Koga et al. (2002) sugere ainda que, a inativação química do antígeno III pode ser um caminho para o desenvolvimento da vacina contra cárie. Outro provável agente vacinal são o grupo das glicotransferases que, em aos glicanos GTF-1 do S mutans, parecem reduzir drasticamente a sua virulência (MUNRO et al., 1993)

As doenças periodontais são infecções bacterianas que resultam em danos nos tecidos de sustentação e suporte dos dentes na cavidade oral (FILOCHE et al., 2010). Segundo Zarco et al. (2012), após a formação da bolsa periodontal, a periodontite evolui para uma classificação de perda irreversível e seu tratamento se torna emergencial. Outros agentes podem interferir na progressão/desenvolvimento da periodontite, como agentes físicos, químicos ou ainda, estes fatores associados à má função do sistema de defesa do indivíduo. Má higienização e hábitos nocivos, como 
etilismo e tabagismo, além de doenças crônicas, favorecem a rápida progressão da doença periodontal (NAIFF; ORLANDI; SANTOS, 2012). Já Cardoso et al. (2009) caracterizam doença periodontal como uma resposta imunológica exacerbada, na tentativa de combater a agressão oriunda de bactérias de alta patogenia para o periodonto.

Em quadros clínicos de periodontite, verifica-se um "start" imunológico de caráter primário, logo após a colonização do sulco gengival pelos micro-organismos que induzem o desenvolvimento da doença. Neste ponto, eventos imunológicos são observados, como presença de mediadores inflamatórios, produção de citocinas e quimiocinas, expressão de moléculas de adesão e um evidente aumento no calibre dos capilares periféricos. Por conta da cascata de eventos da resposta primária, notase uma migração do infiltrado inflamatório para a região da agressão inicial (FORD; GAMONAL e SEYMOUR, 2010).

A relação dos neutrófilos com o periodonto foi estudada por Page (1992). Foi relatado que os neutrófilos são conhecidos como as principais células envolvidas na defesa periodontal. Estão presentes no sulco gengival e são uma barreira de proteção fisiológica entre o epitélio e o biofilme (ATTSTRÖM e SCHROEDER, 1979). Havendo alguma desordem que dificultaria a adesão dos neutrófilos, o resultado seria algum nível de destruição periodontal. Situações de neutropenia são relatadas por Nussbaum e Shapira (2011), reafirmando a condição periodontal resultante em destruição, por ausência das principais células protetoras. Entretanto; Kartarci, Oyaizu e Van-Dyke (2003) afirmam que, a hiper ação dos neutrófilos em caso de doença oral pode produzir citotoxinas que estimulariam a reabsorção óssea.

Como a efetividade da resposta é variável em cada indivíduo, pode ser que, não havendo suporte suficiente da resposta primária imunológica para a contenção da agressão inicial, seguida de progressão da mesma, outros mecanismos de defesa serão requeridos, como a atuação dos plasmócitos na produção de anticorpos para o controle do processo infeccioso (FORD; GAMONAL e SEYMOUR, 2010). 
Segundo Gemmel, Marshall e Seymor (1997), o avanço da periodontite de estável e reversível para avançada e irreversível, caracteriza-se por uma modificação no infiltrado inflamatório, com aumento significativo da presença de células $\mathrm{B}$, além das células $\mathrm{T}$ - já presentes anteriormente- em decorrência da resistência dos patógenos à resposta imunológica inicial. Anticorpos seriam produzidos imediatamente, como avanço na agressividade da resposta imune.

Em periodontites mais avançadas, a presença de anticorpos pode induzir, de forma indesejada, a reabsorção óssea. Ainda nesta situação clínica, seriam observados altos índices de citocinas pró-inflamatórias e, por conta da sua presença, uma sintomatologia inflamatória exacerbada (ANDRUKHOV et al., 2011).

Lerner (2005) declara que o processo de reabsorção e formação óssea é contínuo e, em um indivíduo saudável, mantem-se equilibrado e regulado por alguns mediadores presentes na ação imunológica- citocinas (interleucinas e fator de crescimento tumoral) e prostaglandinas. O processo dinâmico e equilibrado de remodelação óssea é controlado pelo sistema endócrino e o sistema imunológico (LOPES et al., 2008).

Em casos de patologias que desencadeiem o aumento brusco desses mediadores, o processo de reabsorção/remodelação ósseo entraria em desequilíbrio e, muito provavelmente, a reabsorção óssea se tornaria maior. Bartold et al. (2010) diz ainda que o grande número das citocinas presentes e suas moléculas liberadas, além da crônica migração de células inflamatórias, potencializa a reabsorção de tecidos ósseos.

Lins et al. (2007) afirma que os osteoclastos são hiper estimulados pelas citocinas devido à sua origem: formadas pela fusão dos precursores da linhagem dos monócitos/macrófagos. Outra citocina presente é a Interleucina 1 (IL-1), que estimula a função dos osteoclastos e a quimiotaxia dos neutrófilos e macrófagos. Lerner (2005) relata a presença abundante de citocinas em regiões onde existe diagnóstico clínico de gengivite e que as prostaglandinas podem induzir a formação óssea. 
Observa-se uma relação direta entre o grau de destruição tissular e o equilíbrio complexo das citocinas presentes nos diferentes níveis de progressão da periodontite. O gatilho para a liberação das citocinas está relacionado à complexidade e quantidade de agentes patológicos presentes no desenvolvimento da injúria (FORD; GAMONAL e SEYMOUR, 2010).

Uma forma efetiva de investigar e caracterizar a presença de mediadores de inflamação é através coleta de saliva (PAGE, 1992). Entretanto, Teles et al. (2009) afirmam não haver relação direta específica entre as citocinas encontradas na coleta salivar e o grau de desenvolvimento da doença periodontal.

Apesar dos estudos sobre o tema, na rotina odontológica, o diagnóstico das doenças bucais parece restrito apenas à parâmetros clínicos, o que poderia se justificar pela falta de conhecimento dos profissionais sobre a complexidade dos elementos externos e internos relacionados à estas doenças e o caráter único de expressão em cada indivíduo.

\section{CONCLUSÃO}

Na prática clínica, a periodontite e cárie dentária tem como principais elementos de diagnóstico, a observação clínica e história da doença. Outras possibilidades de complementação diagnóstica, como o apontamento da flora microbiana específica existente naquele processo patológico, são constantemente negligenciadas, o que se comprova ser um erro. A pesquisa e levantamento da população microbiana presente, bem como a competência imunológica do paciente, facilitariam um diagnóstico preciso e indicariam apontamentos para um plano de tratamento assertivo e individualizado. Sob a perspectiva da prevenção, pesquisas acerca dos aspectos imunológicos relacionados às doenças de maior incidência oral poderiam proporcionar o desenvolvimento de impedidores definitivos do seu desenvolvimento. Mais estudos e divulgação do âmbito imunológico faz-se necessário entre os profissionais da Odontologia. 


\section{REFERÊNCIAS}

AGUIAR, V. et al. Metagenomics, metatranscriptomics, and metabolomics approaches for microbiome analysis: supplementary issue: bioinformatics methods and applications for big metagenomics data. Evol Bioinform 12:EBOS36436, 2016.

AKIYOSHI, N. et al. Quantificação da IgA secretora e sua correlação com os níveis salivares de estreptococos mutans e lactobacilus em crianças de 7-8 anos de idade. Rev Odontol Univ São Paulo, v.12, n.2, p.129-36, 1998.

ANDRUKHOV, $O$ et al. Serum Cytokine Levels in Periodontitis Patients in Relation to the Bacterial Load. J Periodontol. v. 82, p. 885-892, 2011.

ATTSTRÖM, R; SCHROEDER, H.E. Effect of experimental neutropenia on initial gingivitis in dogs. Scand J Dent Res. v. 87, p.7-23, 1979

BARTOLD, M. P.; CANTLEY, M. D.; HAYNES, D. R. Mechanisms and control of pathologic bone loss in periodontitis. Periodontology 2000, Malden, v. 53, n. 1, p. 55-69, jun. 2010.

CARDOSO, C.R. et al. Evidence of the presence of $T$ helper type 17 cells in chronic lesions of human periodontal disease. Bucal Microbiol Immunol. v. 24, p. 1-6, 2009.

CHUNG, W.O; HANSEN, S.R; RAO, D; DALE, B.A. Protease-activated receptor signaling increases epithelial antimicrobial peptide expression. J Immunol. v. 173, p. 5165-5170, 2004.

DAGLI, N. et al. Oral microbial shift: factors afecting the microbiome and prevention of oral disease. J Contemp Dent Pract 17(1):90-96. 2016. https://doi.org/10.5005/jpjournals-10024-1808 
DEAS D. E; MACKEY, S.A; MCDONNELL, H.T. Systemic disease and periodontitis: manifestations of neutrophil dysfunction. Periodontology 2000. v.32, p. 82-104, 2003.

FLEMMING, H.C. et al. Biofilms: an emergent form of bacterial life. Nat Rev Microbiol. 2016; 14(9): 563-75. [PubMed: 27510863]

FORD, P.J; GAMONAL, J; SEYMOUR, G. Immunological differences and similarities between chronic periodontitis and aggressive periodontitis. Periodontology 2000. v. 53, p.111-123, 2010.

GEMMELL, E.; MARSHALL, R.; SEYMOUR, G.J. Cytokines and prostaglandins in immune homeostasis and tissue destruction. Periodontology 2000. v. 14, p. $112-$ 143, 1997.

HOBLEY, L. et al. Giving structure to the biofilm matrix: an overview of individual strategies and emerging common themes. FEMS Microbiol Rev. 2015; 39(5):64969. [PubMed: 25907113]

KANTARCI, A; OYAIZU, K; VAN-DYKE, T.E. Neutrophil-mediated tissue injury in periodontal disease pathogenesis: findings from localized aggressive periodontitis. J Periodontol. v. 74, p. 66- 75, 2003.

KOGA, T. el al. Immunization Against Dental Caries. Vaccine, Netherlands, v. 20, no-16, p 2027-2044, may. 2002

LERNER, U. H. New molecules in the tumor necrosis factor ligand and receptor superfamilies with importance for physiological and pathological bone resorption. Critical Reviews in Oral Biology and Medicine, Umeä, v. 15(2), p. 64-81, 1 jan. 2004.

LEUNG, T.L.F.; POULIN, R. Parasitism, commensalism, and mutualism: exploring the many shades of symbioses. Vie et Milieu 58(2):107-115, 2008. 
LINS, R. D.A.U.; PEQUENO, M. T.; MELO, J. P. L. C.; FERREIRA, R. C. Q.; SILVEIRA, E. J. D.; DANTAS, E. M. Bone Resorption in Periodontal Disease: the Role of Cytokines and Prostaglandins. Revista de Cirurgia Traumatologia BucoMaxilo-Facial, Camaragibe, v. 7, n.2, p. 29-36, abr./jun. 2007.

LOESCHE, W.J. Cárie dental: uma infecção tratável. Rio de Janeiro: Cultura Médica, 1993. p.309-43.

LOPES, J.C; CANHÃO, H.; FONSECA, J.E. Osteoimmunology - The hidden immune regulation of bone. Revista Autoimmun, Lisboa, v 8(3), p. 250-255, 21 agosto 2008 .

MORRIER, J.J.; BARSOTI, O. Secretory IgA and the oral cavity: general review. Acta Odontostomatol, v.44, n.170, p.349-63. 1990.

MUNRO, G. H. et al. A protein fragment of Streptoccocal Cell Surface Antigen I/II wich Prevent Adhesion of S. mutans. Infect. Immuno. Washington, v. 61, № 11, p 45904598, nov. 1993.

NAIFF, P. F.; ORLANDI, P.P.; SANTOS, M. C. Imunologia da periodontite crônica: uma revisão de literatura. Scientia Amazonia, v. 1, n.2, 28-36, 2012. Revista on-line http://www.scientia.ufam.edu.br ISSN:2238.1910

NUSSBAUM, G; SHAPIRA, L. How has neutrophil research improved our understandig of periodontal pathogenesis. J. Clin. Periodontol., v. 38, p. 49-59, 2011.

PAGE, R.C: Host response tests for diagnosing periodontal diseases. J Periodontol. p. 356-366, 1992.

PITTS, N.B. et al. Dental caries. Nat Rev Dis Primers. 2017; 3:17030. [PubMed: 28540937]

RENDIMBO, M.R. The microbiota, chemical symbiosis, and human disease. J Mol Biol 426(23):3877-3891. 2014. https://doi.org/10.1016/j.jmb.2014.09.011 
SHREINER, A.B.; KAO, J.Y.; YOUNG, V.B. The gut microbiome in health and in $\begin{array}{llll}\text { disease. Curr Opin } & \text { Gastroenterol }\end{array}$ https://doi.org/10.1097/MOG.0000000000000139

TELES, R.P. et al. Salivary Cytokine Levels in Chronic Periodontitis and Periodontally Healthy Subjects. A cross-sectional Study. J Periodontal Res.v. 44(3), p. 411-417, 2009.

TELLEFSON, L.M.; GERMAINE, G.R. Adherence of Streptococcus sanguis to hidroxyapatite coated with lisozyme and lisozyme-supplemented saliva. Infect Immun, v.51, p.750-9. 1986.

TENOVUO, J. Salivary parameters of relevance for assessing caries activity in individuals and populations. Comm Dent Oral Epidemiol, v.25, n.1, p.82-6. 1997.

URSELL, L.K. et al. Defining the human microbiome. Nutr Rev 70(1):S38-S44. 2012. https://doi.org/10.1111/j.1753-4887.2012.00493.x

$\mathrm{XIAO}$, J. et al. The exopolysaccharide matrix modulates the interaction between 3D architecture and virulence of a mixed-species oral biofilm. PLoS Pathog. 2012; 8(4):e1002623. [PubMed:22496649]

5. YAZAKI, S.C. et al. IgA anti-streptococcus mutans em crianças com e sem cáries dentária. Rev Odontol Univ São Paulo, v.13, n.3, p.211-7, 1999.

WANG, B. et al. The human microbiota in health and disease. Engineering 3(1):7182. 2017. https://doi.org/10.1016/J.ENG.2017.01.008

Enviado: Agosto, 2020.

Aprovado: Outubro, 2020. 